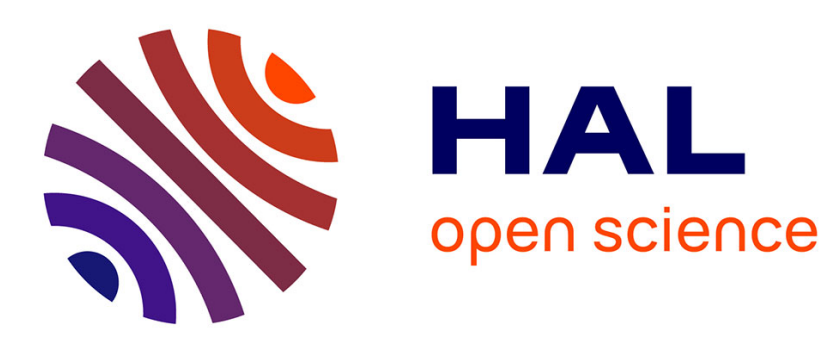

\title{
Regeneracíon de plantas de Paspalum (Gramineae) por cultivo in vitro de anteras
}

\author{
Oscar A. Bovo, Camilo L. Quarin, Luis A. Mroginski
}

\section{To cite this version:}

Oscar A. Bovo, Camilo L. Quarin, Luis A. Mroginski. Regeneracíon de plantas de Paspalum (Gramineae) por cultivo in vitro de anteras. Agronomie, 1985, 5 (10), pp.865-870. hal-00884714

\section{HAL Id: hal-00884714 https://hal.science/hal-00884714}

Submitted on 1 Jan 1985

HAL is a multi-disciplinary open access archive for the deposit and dissemination of scientific research documents, whether they are published or not. The documents may come from teaching and research institutions in France or abroad, or from public or private research centers.
L'archive ouverte pluridisciplinaire HAL, est destinée au dépôt et à la diffusion de documents scientifiques de niveau recherche, publiés ou non, émanant des établissements d'enseignement et de recherche français ou étrangers, des laboratoires publics ou privés. 


\title{
Regeneracíon de plantas de Paspalum (Grami- neae) por cultivo in vitro de anteras
}

\author{
Oscar A. BOVO $(*)$, Camilo L. QUARIN $(* *)$ \& Luis A. MROGINSKI $(* *)$ \\ Instituto de Botánica del Nordeste (IBONE), Facultad de Ciencias Agrarias (UNNE), C.C. 209, Corrientes \\ (3400), Argentina
}

(*) Becario del CONICET

(**) Miembros de la Carrera del Investigador Científico del Consejo Nacional de Investigaciones Cientificas y Técnicas, Argentina

Se regeneraron plantas in vitro a partir de anteras de $P$. quadrifarium $(2 \mathrm{n}=4 \mathrm{x}=40)$ y de $P$. dilatatum ssp. flavescens $\times P$. regnellii $(2 \mathrm{n}=4 \mathrm{x}=40)$, mediante 3 fases de cultivo: 1$)$ Inducción de callos desde anteras conteniendo microsporas recién formadas, mediante su cultivo en el medio de Murashige \& Skoog, suplementado con $1 \mathrm{mg} / 1$ de 2,4-D. 2) Regeneración de vástagos en el mismo medio basal, supplementado con ANA y BAP siendo, respectivamente, 1 y $3 \mathrm{mg} / 1$ las concentraciones que brindaron la mayor cantidad de vástagos. 3) Enraizamiento de los vástagos en el medio basal de MS, pero desprovisto de sustancias reguladoras del crecimiento y con $80 \mathrm{~g} / 1$ de sacarosa. El número de cromosomas de las plantas regeneradas fue $2 \mathrm{n}=4 \mathrm{x}=40$. También fueron cultivadas anteras de $P$. cromyorrhizon $(2 \mathrm{n}=4 \mathrm{x}=40)$, $P$. almum $(2 \mathrm{n}=4 \mathrm{x}=24)$ y de $P$. notatum $(2 \mathrm{n}=4 \mathrm{x}=40)$, en varios medios de cultivo, pero no se indujo la formación de callos.

Palabras claves : Paspalum quadrifarium, Paspalum dilatatum ssp. flavescens $\times \mathrm{P}$, regnellii, apomixis.

La régénération de plantes par culture in vitro d'anthères à partir d'un biotype apomyctique tétraploïde de Paspalum quadrifarium et d'un hybride interspécifique tétraploïde stérile de $P$. dilatatum spp. flavescens $\times P$. regnellii a été réalisée en trois étapes : 1) Induction de cals par culture d'anthères portant de jeunes microspores sur milieu de Murashige \& Skoog avec $1 \mathrm{mg} / 1$ d'acide dichlorophénoxyacétique. 2) Régénération de pousses par culture des cals sur M. \& S. avec $1 \mathrm{mg}$ d'acide naphtalène acétique et $3 \mathrm{mg} / \mathrm{l}$ de 6 benzylaminopurine. 3) Enracinement des pousses sur M. \& S. avec 8 p. 100 de sucrose mais sans hormones. Les plantes régénérées possèdent $2 \mathrm{n}=4 \mathrm{x}=40$ chromosomes. Les cultures d'anthères de $P$. notatum $(2 \mathrm{n}=4 \mathrm{x}=40)$, $P$. almum $(2 \mathrm{n}=4 \mathrm{x}=24)$ et de $P$. cromyorrhizon $(2 \mathrm{n}=4 \mathrm{x}=40)$ sur divers milieux $n$ 'ont produit aucun cal.

Mots clés additionnels : Paspalum quadrifarium, Paspalum dilatatum spp. flavescens $\times$ P. regnellii, apomixie.

Plants were readily regenerated from a tetraploid apomictic biotype of $P$. quadrifarium and from a sterile tetraploid interspecific hybrid of $P$. dilatatum spp. flavescens $\times P$. regnellii by in vitro anther culture through three steps : 1) callus induction by culture of anthers bearing young microspores, on MURASHige \& SKOOG medium with $1 \mathrm{mg} / 1$ 2.4-dichlorophenoxyacetic acid ; 2) shoot regeneration by culture of anther-derived calli on MS with $1 \mathrm{mg} / 1$ naphthalenacetic acid and $3 \mathrm{mg} / 1$ 6-benzyl amino purine, and 3) rooting of shoots on MS (with $8 \%$ sucrose), without hormones. The chromosome number of the regenerated plants was $2 \mathrm{n}=4 \mathrm{x}=40$. Anther cultures of $P$. notatum $(2 \mathrm{n}=4 \mathrm{x}=40)$, $P$. almum $(2 \mathrm{n}=4 \mathrm{x}=24)$ and $P$. cromyorrhizon $(2 \mathrm{n}=4 \mathrm{x}=40)$ on various media did not produce any calli.

Additional key words : Paspalum quadrifarium, Paspalum dilatatum spp. flavescens $\times$ P. regnellii, apomixis. 


\section{INTRODUCCION}

El género Paspalum comprende alrededor de 400 especies, muchas de las cuales son importantes forrajeras naturales en los trópicos y subtrópicos del nuevo mundo. Algunas especies tienen distintos citotipos, siendo los diploides y tetraploides los más frecuentes. Las plantas diploides se reproducen sexualmente, mientras que las tetraploides generalmente son apomícticas. La obtención de dihaploides a partir de citotipos tetraploides podría ser de utilidad para comprender el origen de éstos, como asimismo, para estudiar los mecanismos genéticos de la apomixis. Además, la obtención de dihaploides y su posterior duplicación cromosómica, podría ser uno de los procedimientos a emplearse para obviar los problemas de esterilidad de algunos híbridos interespecíficos tetraploides, obtenidos en el IBONE.

El empleo de las técnicas del cultivo in vitro de anteras, granos de polen u ovarios, han posibilitado la obtención de plantas haploides de varias especies (ver revisiones de CHU, 1982; BAJAJ, 1983). En el género Paspalum, si bien fue factible la regeneración de plantas por cultivo in vitro de ovarios no fecundados de $P$. almum, su número cromosómico fue igual al de las plantas de las que se extrajeron los ovarios (Bovo \& QUARIN, 1983).

En este trabajo se informa acerca de los resultados obtenidos con el cultivo de anteras de 4 especies y un híbrido interespecífico de Paspalum.

\section{MATERIALES Y METODOS}

Se cultivaron anteras de citotipos tetraploides apomícticos de Paspalum almum Chase $(2 \mathrm{n}=4 \mathrm{x}=24)$, $P$. notatum Flügge $(2 \mathrm{n}=4 \mathrm{x}=40), P$. cromyorrhizon Trin. $(2 \mathrm{n}=4 \mathrm{x}=40), P$. quadrifarium Lam. $(2 \mathrm{n}=4 \mathrm{x}=40)$. También se cultivaron anteras del híbrido estéril $(2 \mathrm{n}=4 \mathrm{x}=40), P$. dilatatum spp. flavescens R.A.I. $\times P$. regnellii Mez. Todo este material se mantiene cultivado en la Facultad de Ciencias Agrarias (UNNE) y conservado en el herbario CTES.

La incubación de las anteras fue realizada durante la primavera del año 1983, con excepción de $P$. almum, cuyas anteras fueron cultivadas todos los años a partir de 1979, durante primavera y verano. En todos los casos las anteras incubadas provenían de plantas que crecían en condiciones de campo.

Previa extracción de las anteras, las inflorescencias fueron desinfectadas con $\mathrm{NaOCl}$ al $0,8 \%$ durante $10 \mathrm{mn}$ y posteriormente, lavadas con agua destilada estéril varias veces. En todos los casos se incubaron anteras provenientes de la parte media de las inflorescencias, conteniendo microsporas recién formadas. Para su determinación se empleó orceína acética. En su mayor parte las anteras cultivadas contenían microsporas en estados 2 y 3 de acuerdo con lo descripto por SUNDERLAND (1974) para Datura innoxia.

Se incubaron tres anteras por tubo de ensayo $(150 \times 15 \mathrm{~mm})$ conteniendo $5 \mathrm{ml}$ de medio de cultivo, compuesto - salvo indicación en contrario - de las sales minerales, vitaminas, $3 \%$ de sacarosa y $0,8 \%$ de agar, de acuerdo con MURASHIGE \& SKOOG (1962) (en adelante MS). El medio MS fue suplementado con distintas combinaciones y concentraciones - que se detallan en Resultados - de ácido 2,4-diclorofenoxiacético (2,4-D), ácido naftalenacético (ANA) y 6-bencilaminopurina (BAP). En el caso del cultivo de anteras de $P$. almum, también se utilizaron otros medios que se especifican en la tabla 1, como asimismo se ensayaron otras sustancias reguladoras del crecimiento como ser : 6-furfurilaminopurina (KI) y 6 (gama, gama-dimetilalilamino)-purina (2iP).

$\mathrm{El} \mathrm{pH}$ de los medios de cultivo fue ajustado, antes del agregado del agar, a 5,8 con $\mathrm{HCl}$ y/o $\mathrm{NaOH}$. Los medios de cultivo fueron esterilizados a una atmósfera de presión durante $20 \mathrm{mn}$. Las experiencias fueron repetidas por lo menos 2 o 3 veces.

Para la inducción de callos, las anteras fueron cultivadas en oscuridad $\left(27 \pm 1^{\circ} \mathrm{C}\right)$. Los callos obtenidos fueron subcultivados a medios frescos cuya composición se detalla en Resultados - y se incubaron en 14 horas de luz $\left(10 \mathrm{~W} / \mathrm{m}^{2}\right)$, suministrada por lámparas fluorescentes tipo "Grolux », y 10 horas de oscuridad a una temperatura constante de $27 \pm 1{ }^{\circ} \mathrm{C}$. Los vástagos obtenidos fueron enraizados mediante su cultivo en el medio de MS modificado ( $8 \%$ de sacarosa). Las plantas obtenidas fueron transferidas a una mezcla de tierra y turba $(2: 1)$ y cubiertas con polietileno.

El número cromosómico de las plantas obtenidas in vitro fue determinado en ápices de raíces, los que fueron petratados con una solución saturada de 1-bromonaftaleno durante 2 horas, fijados con alcohol absoluto - ácido acético $(3: 1)$, hidrolizados con $\mathrm{HCl} 1 \mathrm{~N}$ durante $10 \mathrm{mn}$ y coloreados con la técnica de Feulgen.

\section{RESULTADOS Y DISCUSION}

\section{A. Inducción de callos de anteras}

Se llevaron a cabo experiencias con 5 especies de Paspalum que, en el caso de $P$. almum, involucraron el cultivo de 7000 anteras, en 34 condiciones de cultivo diferentes. Sin embargo, nunca se obtuvieron callos; las anteras, luego de 15 a 20 días de cultivo, no experimentaron mayores cambios morfológicos y finalmente ennegrecieron. Algunos resultados figuran en la tabla 1. La obtención de callos de anteras tampoco fue conseguida con la utilización del medio de cultivo de BLAYDES (1966), ni con modificaciones en la concentración de sacarosa (entre 7,5 y $80 \mathrm{~g} / \mathrm{l}$ ), ni con diferentes combinaciones entre varias concentraciones de 2,4-D, ANA, BAP y 2iP. El uso de sustancias antioxidantes como el ácido ascórbico $(5 \mathrm{mg} / \mathrm{l})$ y el cultivo de anteras en medios líquidos estacionarios, con diferentes densidades de anteras (de 3 hasta 120 anteras por $\mathrm{ml}$ ), no posibilitaron la obtención de callos. Los resultados obtenidos con $P$. cromyorrhizon y $P$. notatum son similares a los descriptos para $P$. almum.

El comportamiento de las anteras de $P$. quadrifarium fue diferente. Cuando fueron cultivadas en MS + $1 \mathrm{mg} / \mathrm{l}$ de 2,4-D (tabla 1), inicialmente tendian a adquirir una coloración marrón o negra. Al cabo de 20 a 60 días de incubación, comenzó a observarse la proliferación de callos que, después de 45 días 
TABLA 1

Efecto de diferentes medios de cultivo sobre la induccion de callos desde anteras de Paspalum almum y de P. quadrifarium, cultivadas in vitro durante 60 días.

Effect of various culture media on the induction of calli from anthers

of both Paspalum almum and P. quadrifarium cultured in vitro after 60 days.

\begin{tabular}{|c|c|c|c|c|c|c|c|c|}
\hline \multicolumn{5}{|c|}{$\begin{array}{l}\text { Medio Básico }\left({ }^{1}\right) \\
(0,8 \% \text { de agar) }\end{array}$} & \multicolumn{2}{|c|}{$\begin{array}{l}\text { Reguladores del } \\
\text { Crecimiento } \\
\text { (mg/l) }\end{array}$} & \multicolumn{2}{|c|}{$\begin{array}{c}\text { Inducción de Callos } \\
\text { Desde Anteras } \\
\left({ }^{2}\right)\end{array}$} \\
\hline \multicolumn{2}{|c|}{ Sales Minerales } & \multirow{2}{*}{\multicolumn{2}{|c|}{ Vitaminas }} & \multirow{2}{*}{$\begin{array}{c}\text { Sacarosa } \\
\mathrm{gr} / \mathrm{l}\end{array}$} & \multirow{2}{*}{$2,4-\mathrm{D}$} & \multirow{2}{*}{ KI } & \multirow{2}{*}{ P. almum } & \multirow{2}{*}{ P. quadrifarium } \\
\hline Macronutrientes & Micronutrientes & & & & & & & \\
\hline MS & MS & & MS & 30 & de 0,1 a 10 & 0,1 y 1 & $200 / 0$ & - \\
\hline MS & MS & & MS & 30 & 1 & 0 & $83 / 0$ & $12 / 7$ \\
\hline \multirow{2}{*}{$\begin{array}{c}1 / 2 \mathrm{MS} \\
\mathrm{B} 5\end{array}$} & $1 / 2 \mathrm{MS}$ & $1 / 2$ & MS & 15 & de 0,1 a 1 & 0,1 y 1 & $85 / 0$ & - \\
\hline & B5 & & B5 & 20 & 0,1 & 1 & $15 / 0$ & - \\
\hline
\end{tabular}

(1) MS = Murashige \& SKOOg (1962); B5 = Gamborg et al. (1968).

(2) El numerador indica el total de tubos cultivados ( 3 anteras/tubo) y el denominador el número de tubos con callos.

alcanzaron $15 \mathrm{~mm}$ de diámetro. Los callos fueron esféricos, compactos y de color amarillo o marrón (fig. 1a).

Posteriormente se estudió el efecto de la adición al MS de 2,4-D (1 y $3 \mathrm{mg} / \mathrm{l})$ y BAP $(0$ y $1 \mathrm{mg} / \mathrm{l})$ en el cultivo de anteras de $P$. quadrifarium y de anteras del híbrido $P$. dilatatum flavescens $\times P$. regnellii. En el caso de $P$. quadrifarium (tabla 2), si bien se indujo la proliferación callosa en los 4 medios de cultivo ensayados, el mayor número de tubos con callos fue obtenido con la incorporación de únicamente $1 \mathrm{mg} / \mathrm{l}$ de 2,4-D que además, posibilitó el mejor crecimiento calloso. En cambio, con las anteras del híbrido $P$. dilatatum flavescens $\times P$. regnellii (tabla 2 ), la inducción de callos se produjo con $1 \mathrm{mg} / 1 \mathrm{de} 2,4-\mathrm{D}$ y con $3 \mathrm{mg} / \mathrm{l}$ de $2,4-\mathrm{D}+1 \mathrm{mg} / \mathrm{l}$ de BAP.

\section{B. Regeneración de vástagos a partir de callos}

Los callos (o porciones de los mismos) obtenidos por el cultivo de anteras de $P$. quadrifarium y de $P$. dilatatum flavescens $\times P$. regnellii, fueron cultivados en MS suplementado con ANA y BAP. Al cabo de 20 días de cultivo, en algunos callos se regeneraron vástagos verdes - con un promedio de 7 vástagos por callo (fig. 1b) - que, a los 40 días de cultivo alcanzaron una altura de $6 \mathrm{~cm}$. Una pequeña proporción de los vástagos regenerados fueron deficientes en clorofila. En el caso de los callos de anteras de $P$. quadrifarium, si bien todas las combinaciones de ANA y BAP ensayadas (tabla 3) posibilitaron la regeneración de vástagos, el mayor porcentaje fue obtenido con $1 \mathrm{mg} / \mathrm{l}$ de ANA + $3 \mathrm{mg} / 1$ de BAP.

TABLA 2

Efecto del 2,4-D y BAP sobre la induccion de callos desde anteras de Paspalum quadrifarium $y$ del híbrido $\mathrm{P}$. dilatatum flavescens $\times \mathbf{P}$. regnellii cultivados durante 60 días. Effect of 2,4-D and BAP on callus induction from anthers

of $\mathrm{P}$. quadrifarium, and the hybrid $\mathrm{P}$. dilatatum flavescens $\times \mathrm{P}$. regnellii after 60 days culture.

\begin{tabular}{|c|c|c|c|c|c|}
\hline \multirow{2}{*}{$\begin{array}{c}\text { Material } \\
\text { Vegetal }\end{array}$} & \multicolumn{2}{|c|}{$\begin{array}{l}\text { Reguladores del crecimiento }\left({ }^{1}\right) \\
(\mathrm{mg} / \mathrm{l})\end{array}$} & \multirow{2}{*}{$\begin{array}{l}\mathrm{n}^{\circ} \text { de tubos }\left({ }^{2}\right) \\
\text { cultivados }\end{array}$} & \multirow{2}{*}{$\begin{array}{l}\% \text { de tubos } \\
\text { con callos }\end{array}$} & \multirow{2}{*}{$\begin{array}{c}\text { Tamaño de los }(3) \\
\text { callos }\end{array}$} \\
\hline & $2,4-\mathrm{D}$ & BAP & & & \\
\hline \multirow{4}{*}{ P. quadrifarium } & 1 & 0 & 12 & 58,3 & ++ \\
\hline & 1 & 1 & 15 & 46,7 & + \\
\hline & 3 & 0 & 15 & 53,3 & + \\
\hline & 3 & 1 & 15 & 13,3 & + \\
\hline & 1 & 0 & 15 & 6,7 & + \\
\hline P. dilatatum flavescens & 1 & 1 & 13 & 0 & 0 \\
\hline$x$ & 3 & 0 & 15 & 0 & 0 \\
\hline$P$. regnellii & 3 & 1 & 11 & 9,1 & ++ \\
\hline
\end{tabular}

(') Adicionados a MS.

(2) En cada tubo fueron cultivadas tres anteras.

$\left.{ }^{3}\right)+=$ callos de 3 a $8 \mathrm{~mm}$ de diámetro; $++=$ callos de 8 a $15 \mathrm{~mm}$ de diámetro. 

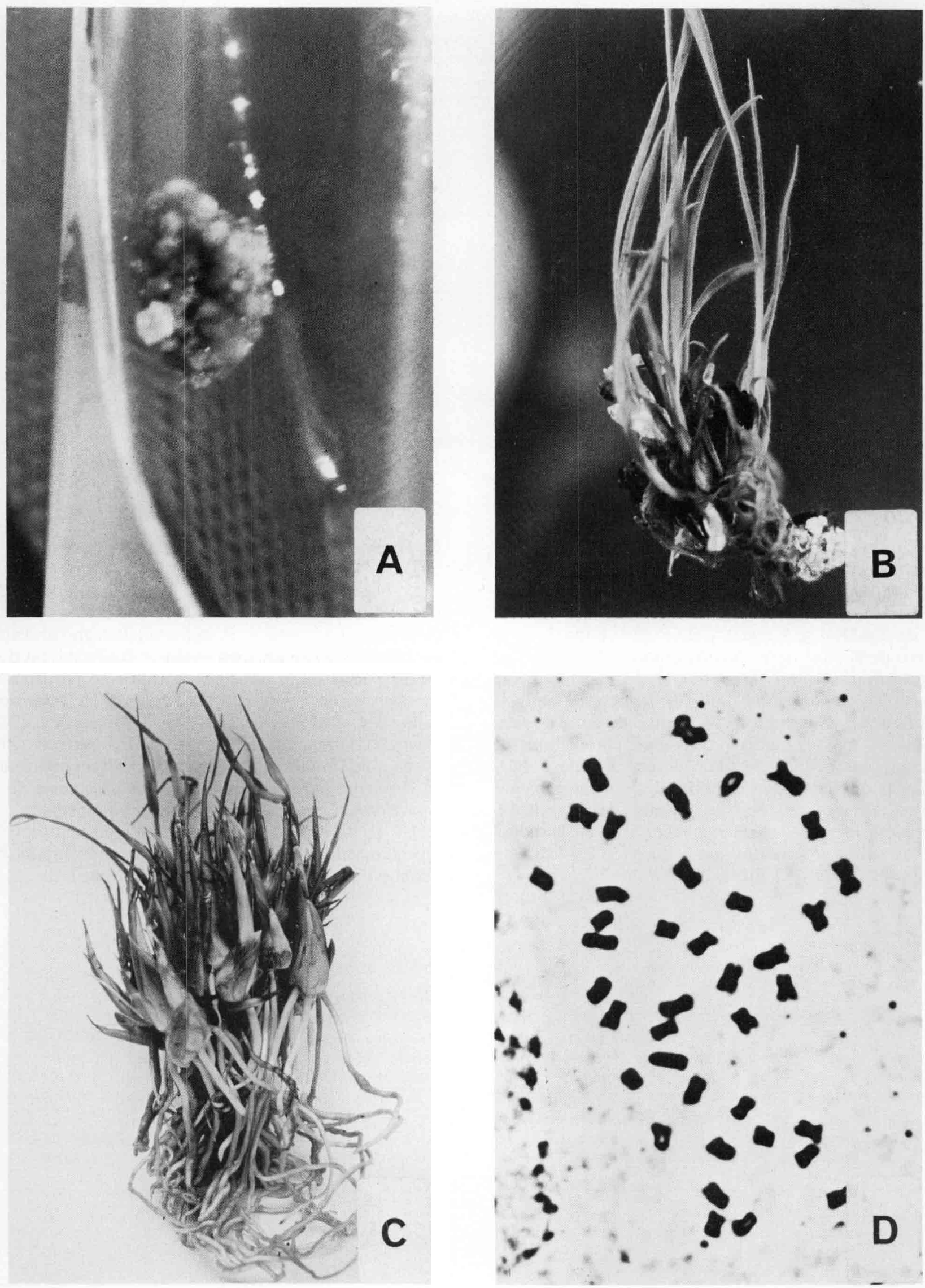

Figura 1

Regeneración de plantas in vitro a partir de callos de anteras de Paspalum quadrifarium. A) Formación de callo en $M S+1 \mathrm{mg} / \mathrm{l}$ de 2,4-D (X 4). B) Regeneración de vástagos en $M S+0,1 \mathrm{mg} / \mathrm{l}$ de ANA $+3 \mathrm{mg} / \mathrm{l}$ de $B A P(X 2)$. C) Enraizamiento de los vástagos en MS con $8 \%$ de sacarosa $(X 2)$. D) Cromosomas mitóticos de ápices radiculares de una planta regenerada in vitro $(X 4000 \%$

Regeneration of plants from anther-derived calli of Paspalum quadrifarium. A) Callus induction on $M S+1 m g / l 2,4-D(X 4)$. B) Shoot regeneration on $M S+0.1 m g / l N A A+3 m g / l B A P$ $(X 2)$. C) Rooting of shoots on $M S$ with $8 \%$ sucrose $(X 2)$. D) Mitoric chromosome from root tip of a plant regenerated in vitro $(X 4000)$ 
TABLA 3

Efecto del ANA y BAP sobre la regeneración de vástagos a partir de callos de anteras de Paspalum quadrifarium $y$ del hibrido $\mathrm{P}$. dilatatum flavescens $\times \mathrm{P}$. regnellii, cultivados durante 60 días.

Effect of $A N A$ and $B A P$ on shoot regeneration from anther calli of Paspalum quadrifarium and the hybrid $\mathrm{P}$. dilatatum flavescens $\times \mathrm{P}$. regnellii after 60 days culture.

\begin{tabular}{|c|c|c|c|c|c|}
\hline \multirow{2}{*}{$\begin{array}{l}\text { Material } \\
\text { Vegetal }\end{array}$} & \multicolumn{2}{|c|}{$\begin{array}{l}\text { Reguladores del Crecimiento (1) } \\
\qquad(\mathrm{mg} / \mathrm{l})\end{array}$} & \multirow{2}{*}{$\begin{array}{l}\mathrm{N}^{\circ} \text { de callos } \\
\text { subcultivados }\end{array}$} & \multicolumn{2}{|c|}{ Callos con vástagos (2) } \\
\hline & ANA & BAP & & $n^{0}$ & 070 \\
\hline \multirow{4}{*}{ P. quadrifarium } & 0,1 & 1 & 17 & 3 & 17,6 \\
\hline & 0,1 & 3 & 18 & 2 & 11,1 \\
\hline & 1 & 1 & 16 & 3 & 18,7 \\
\hline & 1 & 3 & 13 & 4 & 30,7 \\
\hline & 0,1 & 1 & 4 & 1 & 25,0 \\
\hline P. dilatatum flavescens & 0,1 & 3 & 3 & 0 & 0 \\
\hline$x$ & 1 & 1 & 3 & 1 & 33,3 \\
\hline P. regnellii & 1 & 3 & 3 & 0 & 0 \\
\hline
\end{tabular}

(1) Adicionados a MS.

(2) Unicamente se tuvieron en cuenta vástagos mayores de $1 \mathrm{~cm}$.

Nunca se regeneraron vástagos con raíces. La regeneración de vástagos fue independiente de la composición del medio de cultivo utilizado para la inducción de callos desde las anteras. Los callos de las anteras del híbrido $P$. dilatatum flavescens $\times P$. regnellii, cultivados en $\mathrm{MS}$, suplementado con $1 \mathrm{mg} / 1$ de ANA + $1 \mathrm{mg} / \mathrm{l}$ de BAP brindaron plantas enteras, mientras que los que fueron cultivados en $0,1 \mathrm{mg} / 1 \mathrm{de}$ $\mathrm{ANA}+1 \mathrm{mg} / 1$ de $\mathrm{BAP}$, únicamente regeneraron vástagos (tabla 3 ).

\section{Enraizamiento de los vástagos}

Un total de 60 vástagos con restos de callos, fueron cultivados en el medio MS modificado (sacarosa $80 \mathrm{~g} / \mathrm{l}$, en lugar de $30 \mathrm{~g} / \mathrm{l}$ ). A los 20 días de cultivo, tanto en los vástagos obtenidos por cultivo de anteras de $P$. quadrifarium, como en los de $P$. dilatatum flavescens $\times P$. regnellii, se obtuvo una abundante proliferación de raíces (fig. 1c). Las plantas obtenidas fueron trasferidas a una mezcla de tierra y turba.

Los recuentos cromosómicos realizados en 12 plantas de $P$. quadrifarium y 3 de $P$. dilatatum flavescens $\times P$. regnellii mostraron el mismo número de cromosomas de las plantas dadoras de anteras; es decir, $2 n=4 x=40$ (fig. $1 \mathrm{~d}$ ).
Los requerimientos nutritivos para la obtención de callos y plantas a partir del cultivo in vitro de Paspalum no se apartan mayormente de los descriptos para otras gramíneas, donde la sola presencia de la auxina 2,4-D en el medio de cultivo, es suficiente para la inducción de callos (ver revisiones de COLLINS \& GENOVESI, 1982 ; MAHESHWARI et al., 1982 ; NARAYANASWAMY \& GEORGE, 1982 ; SUNDERLAND, 1978). El medio de regeneración de vástagos fue el mismo que generalmente es utilizado para dicha finalidad, a partir del cultivo de otros explantos, como ser inflorescencias y embriones de especies de Paspalum (BOVO, no publicado).

El exitoso enraizamiento de los vástagos obtenidos in vitro con el empleo de concentraciones elevadas de sacarosa, confirma lo observado en caña de azúcar por MARETZKI \& HIRAKI (1980) y por Ho \& VASIL (1983).

Reçu le 20 décembre 1984. Accepté le 21 juin 1985.

\section{AGRADECIMIENTOS}

Agradecemos al Sr. H. VazQuez por la confección de las fotografías.
Bajaj Y. P. S., 1983. In vitro Production of haploids, p. 228-287. In D. A. Evans, W. R. Sharp, P. V. Ammirato \& Y. Yamada: "Handbook of Plant Cell Culture. Volume I. Techniques for Propagation and Breeding ». Macmillan Publishing Co., N.Y., $970 \mathrm{p}$.

Blaydes D. F., 1966. Interaction of kinetin and various inhibitors in the growth of soybean tissues. Physiol. Plant., 19, 748-753.

Bovo O. A., Quarin C. L., 1983. Obtención de plantas de
Paspalum almum (Gramineae) a partir del cultivo in vitro de ovarios jóvenes. Phyton, 43, 29-34.

Chu C. C., 1982. Haploids in plant improvement, p. 129-158. In I. K. Vasil, W. R. Scowcroft \& K. J. Frey : « Plant Improvement and Somatic Cell Genetics. Academic Press, N.Y., 300 p.

Collins G. B., Genovesi A. D., 1982. Anther culture and its application to crop improvement, p. 1-24. In D. T. Tomes, B. E. Ellis, P. M. Harney, K. J. Kasha \& R. J. Peterson : "Application on 
Plant Cell and Tissue Culture to Agriculture \& Industry. University of Guelph, Guelph, Canada, 231 p.

Gamborg O. L., Miller R. A., Ojima K., 1968. Nutrient requirements of suspension cultures of soybean root cells. Exper. Cell. Res., 50, 151-158.

Ho W.-J., Vasil I. K., 1983. Somatic embryogenesis in sugarcane (Saccharum officinarum L.). I. The morphology and physiology of callus formation and the ontogeny of somatic embryos. Protoplasma, 118, 169-180.

Maheshwari S. C., Rashid A., Tyagi A. K., 1982. Haploids from pollen grains : retrospect and prospect. An. J. Bot., 69, 865-879.

Maretzki A., Hiraki P., 1980. Sucrose promotion of root formation in plantlets regenerated from callus of Saccharum spp. Phyton, 38, 85-88.
Murashige T., Skoog F., 1962. A revised medium for rapid growth and bio assays with tobacco tissue culture. Physiol. Plant., 15, 473497.

Narayanaswamy S., George L., 1982. Anther culture, p. 79-103. In B. M. Johri : "Experimental Embryology for Vascular Plants». Springer Verlag, Berlin, 273 p.

Sunderland N., 1974. Anther culture as a means of haploid induction, p. 91-122. In K. J. Kasha : "Haploids in higher plants. Advances and Potencial ". University of Guelph, Canada, $421 \mathrm{p}$.

Sunderland N., 1978. Strategies in the improvement of yield in anther culture, p. 65-68. Proc. Symp. on Plant Tissue Culture. Science Press, Pekin, 531 p. 